\title{
Effects of p38MAPK-mediated excision repair cross-complementation 1 expression on prognosis of patients with non-small cell lung cancer
}

\author{
DAN HE $^{1 *}$, XIAOMEI MA ${ }^{2 *}$, ZHENHUA WU ${ }^{1}$, YANG WANG ${ }^{1}$, SHUYUAN ZHAO ${ }^{1}$, \\ FENG HAN $^{1}$ and WEI SUN ${ }^{1}$ \\ Departments of ${ }^{1}$ Thoracic Surgery and ${ }^{2}$ Pathology, Affiliated Tumor Hospital, Xinjiang Medical University, \\ Urumqi, Xinjiang 830011, P.R. China
}

Received July 11, 2016; Accepted July 13, 2017

DOI: 10.3892/ol.2017.6649

\begin{abstract}
The present study aimed to investigate the effects of excision repair cross-complementation 1 (ERCC1) expression on the prognosis of patients with non-small cell lung cancer (NSCLC). A total of 140 patients with NSCLC who underwent radical resection were included. Immunohistochemical staining was performed on the tissue specimens obtained from patients and correlation analysis was used to determine the association between ERCC1 expression and clinicopathological characteristics. Cell proliferation was assessed using an MTT assay. The mRNA and protein expression levels were detected using reverse transcription-quantitative polymerase chain reaction and western blot analysis, respectively. The expression of ERCC1 was demonstrated to be significantly elevated in tumor tissue compared with adjacent tissue samples. Furthermore, the expression of ERCC1 in squamous carcinoma was significantly higher compared with in adenocarcinoma samples. The expression of ERCC1 in patients who smoke was significantly higher compared with in the non-smokers. The 3-year disease-free survival (DFS) and overall survival (OS) for ERCC1-negative patients were higher compared with ERCC1-positive patients. Multivariate analysis demonstrated that ERCC1 expression, pathological staging, and tumor staging were important prognostic factors for NSCLC. Subgroup analysis revealed that the 3-year OS rate for ERCC1-negative patients with stage II-III tumors who received systematic adjuvant chemotherapy was higher compared with ERCC1-negative patients. The 3-year
\end{abstract}

Correspondence to: Dr Wei Sun, Department of Thoracic Surgery, Affiliated Tumor Hospital, Xinjiang Medical University, 789 Suzhou East Street, Urumqi, Xinjiang 830011, P.R. China

E-mail: sunw69@163.com

*Contributed equally

Key words: non-small cell lung cancer, excision repair cross-complementation 1, p38MAPK, diamminedichloroplatinum
DFS and OS rates for ERCC1-negative patients with squamous carcinoma were higher compared with ERCC1-positive patients. In addition, p38 inhibitor treatment significantly inhibited the mRNA and protein expression levels of ERCC1 in A549 cells, and enhanced the sensitivity of cells to cisplatin. The results of the present study suggest that ERCC1 expression is an important prognostic indicator for NSCLC, particularly for patients with stage II-III tumors who receive systematic platinum-based adjuvant chemotherapy.

\section{Introduction}

Platinum-based two-drug combination chemotherapy is currently the first-line chemotherapy regimen for non-small cell lung cancer (NSCLC) (1). Platinum would be hydrolysed in the tumor cells and form DNA-platinum complex, which prevents the DNA replication to exert cytotoxic effects. However, the resistance of tumor cells against cisplatin would seriously influence the treatment efficacy for NSCLC. Up to now, nucleotide excision repair (NER) has been recognized as one of the important mechanisms for the cisplatin resistance, in which excision repair cross-complementation 1 (ERCC1) is known to be critically involved.

ERCC1 is a single-strand DNA endonuclease, which is located on the 19q13.2 chromosome in human beings. ERCC1 is the rate-limiting enzyme for the NER pathway, which plays an important role in the DNA repairing process. The expression level of ERCC1 reflects the DNA repair capability (DRC). Downregulated DRC expression delays the DNA repairing process and results in increased susceptibility to lung cancers. In contrast, overexpression of ERCC1 contributes to the repairing of DNA-platinum complex, leading to platinum resistance. At present, retrospective clinical studies concerning ERCC1 mainly focus on NSCLC patients at advanced stage and/or after surgery. Due to the differences in experimental design and result evaluation, it is still controversial for the effects of ERCC1 expression on the prognosis of NSCLC (2-5). Several studies show that the expression of ERCC1 can be used as a predictor for the sensitivity to cisplatin (6-9). The mRNA level of ERCC1 in the tumor tissue from patients with advanced NSCLC has been shown to be closely associated with the 
response to the two-drug combination chemotherapy (10). A meta-analysis further shows that ERCC1 is the important indicator for the response rate of patients with advanced NSCLC to platinum and the overall survival (OS) rate (11).

The p38 signaling pathway is an important branch of the MAPK pathway, which is involved in various physiological processes, including inflammation, cell proliferation, and apoptosis (12). As stress signals, chemotherapeutic drugs can activate the p38 signaling pathway in a variety of tumor cells. The p38 signaling pathway has been shown to be closely related to the resistance of tumors, and its inhibitor could enhance the tumor sensitivity to chemotherapeutic agents $(13,14)$. The chemotherapeutic agent-activated p38 MAPK signal breaks the dynamic balance between the p38 and PERK signaling pathways to inhibit the proliferation of tumor cells and force the cells into dormancy, resulting in drug resistance $(15,16)$. Our previous study has shown that the p38 inhibitor BIRB796 could specifically suppress the function of membrane transporter ABCB1, and thereby reverse the drug resistance to chemotherapeutic agents, such as doxorubicin, paclitaxel, and vincristine (17).

Clinical studies concerning the advanced NSCLC patients have confirmed the association between the ERCC1 expression and the cisplatin response rate and disease prognosis. However, inconsistent findings have been obtained for the patients at stages I-III after surgery, and relationship between the p38 signaling pathway and the tumor drug resistance still needs to be elucidated. In this study, the effects of ERCC1 expression on the prognosis of NSCLC were investigated, especially concerning its association with the p38 signaling pathway.

\section{Materials and methods}

Cell line and cell culture. Human lung carcinoma cell line A549 was purchased from ATCC. These cells were cultured with the RPMI-1640 complete medium (Gibco-BRL, Grand Island, NY, USA) containing $10 \%$ fetal calf serum (FCS), supplemented with $2.2 \%(\mathrm{w} / \mathrm{v})$ sodium bicarbonate, $0.03 \%(\mathrm{w} / \mathrm{v})$ L-glutamine, as well as $100 \mathrm{U} / \mathrm{ml}$ penicillin and $100 \mathrm{mg} / \mathrm{ml}$ streptomycin, in a $37^{\circ} \mathrm{C}, 5 \% \mathrm{CO}_{2}$ incubator.

Study subjects. Totally 343 patients with NSCLC (squamous carcinoma or adenocarcinoma) were screened in this study, who had admitted to the Affiliated Tumor Hospital, Xinjiang Medical University and received standard lung cancer resection (i.e., lobectomy and systematic mediastinal lymph node dissection), from January 1, 2010 to December 31, 2013. Inclusion criteria were as follows: i) patients with complete follow-up data; ii) patients who had not received chemotherapy before surgery; iii) patients with cancer at stage II or III who received systematic platinum-based two-drug combination chemotherapy for four cycles or radiotherapy after surgery; iv) patients with cancer at stage I who did not receive systematic chemotherapy until tumor recurrence during the follow-up period; and v) patients from whom the tumor and adjacent tissues were obtained. After screening, 140 patients were finally included in this study. Prior written and informed consent were obtained from every patient and the study was approved by the ethics review board of the Affiliated Tumor Hospital, Xinjiang Medical University.
Post-operative follow-up. These 140 patients with NSCLC were followed up by telephone, which begun from the date of surgery and ended at Jun 1, 2015. Endpoint events included tumor recurrence and patient death. Evaluation indexes included the 1-, 2-, and 3-year disease-free survival (DFS) and OS rates.

Immunohistochemistry. The expression of ERCC1 was detected with immunohistochemistry, according to Hubner et al (18). The tumor and adjacent tissues from NSCLC patients were obtained and cut into $5-\mu \mathrm{m}$ sections. After dewaxing and rehydration, these sections were treated with $3 \% \mathrm{H}_{2} \mathrm{O}_{2}$ for $20 \mathrm{~min}$, followed by antigen retrieval for $10 \mathrm{~min}$. After blocked with serum blocking solution at room temperature for $30 \mathrm{~min}$, these sections were incubated with mouse anti-human anti-ERCC1 monoclonal antibody (1:100 dilution; ab2356; Abcam, Cambridge, MA, USA) at $4{ }^{\circ} \mathrm{C}$ overnight. Then the sections were incubated with biotinylated secondary antibody at $37^{\circ} \mathrm{C}$ for $1 \mathrm{~h}$. After washing, these sections were treated with SABC agent and subjected to DAB colorization. After hematoxylin staining, dehydration, xylene clearing, and neutral resin sealing, the sections were observed under microscope.

Immunohistochemical assessment was performed by two independent senior physicians from the Department of Pathology, according to the evaluation and scoring criteria from Planchard et al (19). Five fields with high magnification (x400) were randomly selected from each section, and totally 100 cells were counted. Semi-quantitative H-score indicating the relative protein expression level was obtained as the product of the staining intensity score and the positive tumor cell percentage. For the staining intensity score: 0 , negative (no staining); 1, weak positive (light yellow staining); 2, positive (dark yellow staining); and 3 , strong positive (brown staining). For the positive tumor cell percentage: 0 , no positive tumor cells; $0.1,1-9 \% ; 0.5,10-50 \%$, and $1.0,>50 \%$.

MTT assay. Cell proliferation was assessed with the MTT assay (20). Briefly, cells were seeded onto 96-well plates and cultured overnight. The cells were pre-incubated with or without the p38MAPK inhibitor BIRB796 (SelleckChem, Houston, TX, USA) for $1 \mathrm{~h}$ and then with diamminedichloroplatinum (DDP; Sigma-Aldrich, St. Louis, MO, USA) at indicated concentrations. After $68 \mathrm{~h}$, these cells were treated with $20 \mu \mathrm{l}$ MTT (4 mg/ml) for $4 \mathrm{~h}$. After the medium was discarded, $120 \mu \mathrm{l}$ dimethylsulfoxide (DMSO) was added into each well. The absorbance at $655 \mathrm{~nm}$ was read by the Model 550 microplate reader (Bio-Rad, Hercules, CA, USA).

Western blot analysis. After treatment, cells were lysed with lysis buffer. The protein concentration was determined, and protein sample was subjected to SDS-PAGE and then transferred onto the nitrocellulose membrane. After blocked with $5 \%$ non-fat milk in TBST at room temperature for $2 \mathrm{~h}$, the membrane was incubated with primary antibodies against p38 (ab170099), p-p38 (ab178867), $\beta$-tubulin (ab6046) and ERCC1 (ab2356) (all from Abcam) at $4^{\circ} \mathrm{C}$ overnight. The membrane was then incubated with HRP-conjugated secondary antibody (1:5,000 dilution; Abcam) at room temperature for $2 \mathrm{~h}$. After washing with TBST, the protein bands were visualized by the 
A

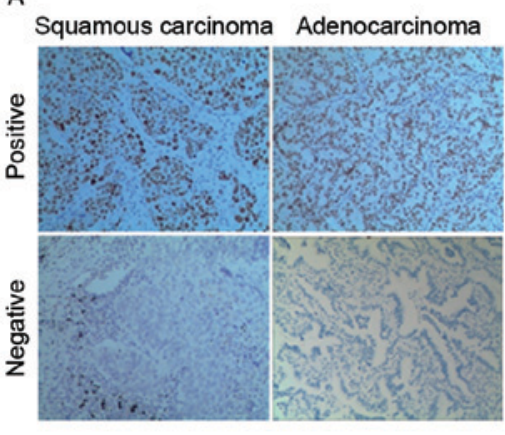

B

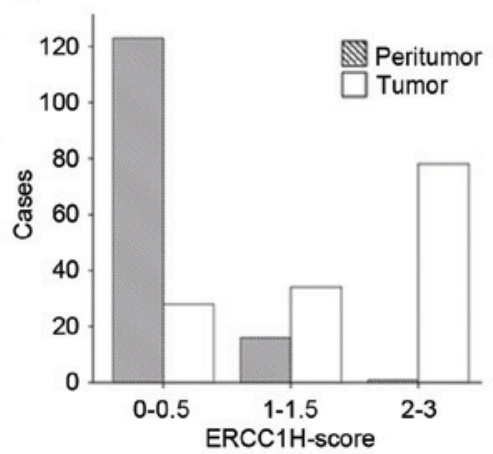

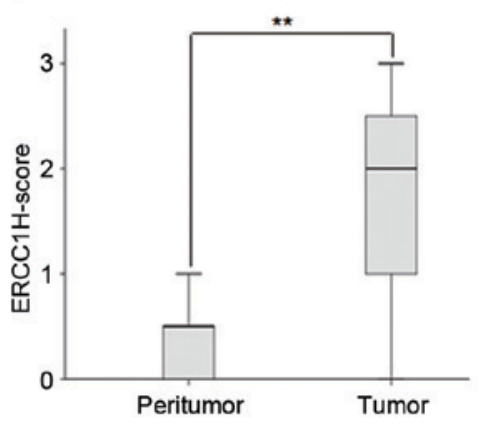

Figure 1. ERCC1 expression in the NSCLC tumor and adjacent tissues. (A) Immunohistochemical staining of ERCC1 for the tissues from squamous carcinoma and adenocarcinoma. ERCC1 was localized in the nucleus. Positive staining: the staining intensity score $>2$, while the positive tumor cell percentage $>50 \%$. (B) Distribution of ERCC1 H-scores in peri-tumor and tumor tissues of 140 NSCLC patients. (C) Box diagram analyzing the ERCC1 expression in the tumor and adjacent tissues. Lower and upper limits of boxes indicate the first and third quartiles; the lines within boxes indicate the median values; and the lines extending from the boxes indicate the range of values. Compared with the adjacent tissue, ${ }^{* *} \mathrm{P}<0.01$. ERCC1, excision repair cross-complementation 1 ; $\mathrm{NSCLC}$, non-small cell lung cancer.

enhanced Phototope ${ }^{\mathrm{TM}}$-HRP Detection kit (Cell Signaling Technology, Beverly, MA, USA) and exposed to Kodak medical X-ray processor (Carestream Health, Rochester, NY, USA). The p38 was used as loading control.

Quantitative real-time PCR. After treatment, total RNA was extracted with the TRIzol reagent RNA Extraction kit (Molecular Research Center, Cincinnati, OH, USA), following the manufacturer's instructions. The first-strand cDNA was synthesized by RevertAid ${ }^{\mathrm{TM}}$ Premium First-Strand cDNA Synthesis kit (Fermentas International Inc., Burlington, ON, Canada). The PCR primer sequences were as follows: ERCC1 forward, 5'-TGTCCAGGTGGATGTGAAAGAT-3' and reverse, 5'-GGCCTTGTAGGTCTCCAGGTA-3'; and GAPDH forward, 5'-TGTTGCCATCAATGACCCCTT-3' and reverse, 5'-CTCCACGACGTACTCAGCG-3'. PCR was performed on the Gene Amp PCR system 9700 (PE Applied Biosystems, Foster City, CA, USA), with the following conditions: Denaturation at $94^{\circ} \mathrm{C}$ for $2 \mathrm{~min}$; then $95^{\circ} \mathrm{C}$ for $30 \mathrm{sec}, 61^{\circ} \mathrm{C}$ for $30 \mathrm{sec}$, and $72^{\circ} \mathrm{C}$ for $1 \mathrm{~min}$, for totally 30 cycles; followed by extension at $72^{\circ} \mathrm{C}$ for $10 \mathrm{~min}$. Products were resolved and examined by $1.0 \%$ agarose gel electrophoresis. Quantitative real-time PCR was performed on the Bio-Rad CFX96 ${ }^{\mathrm{TM}}$ real-time system (Applied Biosystems, Framingham, MA, USA). Relative mRNA expression levels of ERCC1 were determined with the $2^{-\Delta \Delta \mathrm{Ct}}$ method.

Statistical analysis. SPSS20.0 software was used for statistical analysis. The $\chi^{2}$ test and non-parametric Wilcoxon rank sum test were performed for the comparison of clinical data. The Kaplan-Meier analysis with Breslow test was used for the survival analysis. Cox regression model was applied for the multivariate analysis. $\mathrm{P}<0.05$ was considered as statistically significant.

\section{Results}

ERCC1 expression is elevated in NSCLC tumor tissue. To investigate the expression levels of ERCC1 in the NSCLC tumor and adjacent tissues, immunohistochemistry was performed. Positive and negative staining of ERCC1 in the tissues from NSCLC (squamous carcinoma and adenocarcinoma) was shown in Fig. 1A. The positive staining of ERCC1 was mainly located in the nucleus. The H-score assessment showed that for the tumor tissues, the median H-score was 2, which was higher than the median $\mathrm{H}$-score for the adjacent tissues $(0)(\mathrm{P}<0.01)$ (Fig. 1B and $\mathrm{C})$. When H-score $\geq 2.0$ in the tumor tissue was considered as positive (i.e., the staining intensity score $>2$ while the positive tumor cell percentage $>50 \%$ ), the positive staining percentage for the tumor tissue was $46.4 \%$ (65/140). These results suggest that the expression level of ERCC1 is upregulated in the NSCLC tumor tissue.

ERCC1 is associated with NSCLC pathological type, histological grade, and patient smoking status. The association between the ERCC1 expression and clinicopathological features of NSCLC was next investigated. As shown in Table I, the expression of ERCC1 is associated with the NSCLC pathological type. The expression level of ERCC1 in the squamous carcinoma $(59.3 \%, 35 / 59)$ was significantly higher than the adenocarcinoma $(37 \%, 30 / 81)(\mathrm{P}<0.01)$. Moreover, significant differences were observed in the ERCC1 expression levels between different histological stages $(\mathrm{P}<0.05)$, and the expression level of ERCC1 showed an increasing trend along with the decreasing differentiation degrees. Furthermore, the expression level of ERCC1 for the smoking patients $(60.3 \%, 41 / 68)$ was significantly higher than the non-smokers $(33.3 \%, 24 / 72)$ $(\mathrm{P}<0.01)$. On the other hand, the ERCC1 expression was not significantly associated with the other investigated clinicopathological features, including age, sex, pathological staging, $\mathrm{T}$ staging, $\mathrm{N}$ staging, and history of radio- and/or chemotherapy. These results suggest that the expression of ERCC1 is significantly associated with the NSCLC pathological type, histological grade, and patient smoking status.

ERCCl affects postoperative prognosis of NSCLC patients. The association between the ERCC1 expression and postoperative prognosis of NSCLC was next investigated. Our results showed that in the term of DFS, for the ERCC1-positive NSCLC patients, the 1-, 2-, and 3-year DFS rates were 79.8, 69.1, and 
Table I. Relationship between the ERCC1 expression in tumor tissue and clinicopathological features of NSCLC.

\begin{tabular}{|c|c|c|c|c|c|}
\hline & \multirow[b]{2}{*}{ Total cases, $\mathrm{n}(\%)$} & \multicolumn{2}{|c|}{ Tumor ERCC1 expression } & \multirow[b]{2}{*}{$\chi^{2}$} & \multirow[b]{2}{*}{ P-value } \\
\hline & & Positive, n (\%) & Negative, n (\%) & & \\
\hline Age (years) & & & & 5.596 & 0.061 \\
\hline$<50$ & $20(14.3)$ & $14(70.0)$ & $6(30.0)$ & & \\
\hline $50-70$ & $95(67.8)$ & $39(41.0)$ & $56(59.0)$ & & \\
\hline$>70$ & $25(17.9)$ & $12(48.0)$ & $13(52.0)$ & & \\
\hline Sex & & & & 0.161 & 0.689 \\
\hline Male & $88(62.9)$ & $42(47.7)$ & $46(52.3)$ & & \\
\hline Female & $52(37.1)$ & $23(44.2)$ & $29(55.8)$ & & \\
\hline Histological type & & & & 6.816 & 0.009 \\
\hline Squamous cancer & $59(42.1)$ & $35(59.3)$ & $24(40.7)$ & & \\
\hline Adenocarcinoma & $81(57.9)$ & $30(37.0)$ & $51(63.0)$ & & \\
\hline Histological grade & & & & 7.665 & 0.022 \\
\hline G1 & $59(42.1)$ & $35(59.3)$ & $24(40.7)$ & & \\
\hline G2 & $57(40.7)$ & $23(40.4)$ & $34(59.6)$ & & \\
\hline G3 & $24(17.2)$ & $7(29.2)$ & $17(70.8)$ & & \\
\hline pTNM & & & & 2.094 & 0.351 \\
\hline Stage I & $50(35.7)$ & $23(46.0)$ & $27(54.0)$ & & \\
\hline Stage II & $35(25.0)$ & $13(37.1)$ & $22(62.9)$ & & \\
\hline Stage III & $55(39.3)$ & $29(52.7)$ & $26(47.3)$ & & \\
\hline T stage & & & & 1.264 & 0.532 \\
\hline $\mathrm{T} 1$ & $34(24.2)$ & $16(47.1)$ & $18(52.9)$ & & \\
\hline $\mathrm{T} 2$ & $81(57.9)$ & $35(43.2)$ & $46(56.8)$ & & \\
\hline $\mathrm{T} 3$ & $25(17.9)$ & $14(56.0)$ & $11(44)$ & & \\
\hline $\mathrm{N}$ stage & & & & 1.129 & 0.569 \\
\hline N0 & $74(52.9)$ & $33(44.6)$ & $41(55.4)$ & & \\
\hline N1 & $18(12.9)$ & $7(38.9)$ & $11(61.1)$ & & \\
\hline $\mathrm{N} 2$ & $48(34.2)$ & $25(52.1)$ & $23(47.9)$ & & \\
\hline Smoking status & & & & 10.22 & 0.001 \\
\hline Non-smoker & $72(51.4)$ & $24(33.3)$ & $48(66.7)$ & & \\
\hline Smoker & $68(48.6)$ & $41(60.3)$ & $27(39.7)$ & & \\
\hline Chemoradiotherapy & & & & 0.838 & 0.36 \\
\hline No & $61(43.6)$ & $31(50.8)$ & $30(49.2)$ & & \\
\hline Yes & $79(56.4)$ & $34(43.0)$ & $45(57.0)$ & & \\
\hline
\end{tabular}

Smokers were defined as patients with the smoking habit for 10 years (10 cigarettes/day). ERCC1, excision repair cross-complementation 1; NSCLC, non-small cell lung cancer.

$53.4 \%$, respectively, with the median DFS of $22.17 \mathrm{~m}$ (ranging from 9.85 to $34.49 \mathrm{~m})$. On the other hand, the 1-, 2-, and 3-year DFS rates for the ERCC1-negative NSCLC patients were 85.9, 76.8 , and $66.8 \%$, respectively, with the median DFS of $28.4 \mathrm{~m}$ (ranging from 19.34 to 37.46 m) (Table II). The Kaplan-Meier survival analysis showed that the DFS for ERCC1-negative patients was superior to the ERCC1-positive patients (Fig. 2A). In the term of the OS, for the ERCC1-positive NSCLC patients, the 1-, 2-, and 3-year OS rates were 88.4, 67.9, and $64.7 \%$, respectively, with the median OS of $51.93 \mathrm{~m}$ (ranging from 41.69 to $62.17 \mathrm{~m}$ ). On the other hand, the 1-, 2-, and 3-year OS rates for the ERCC1-negative NSCLC patients were 94.2, 87.1 , and $84.2 \%$, respectively (Table II). The survival analysis showed that the OS for ERCC1-negative patients was superior to the ERCC1-positive patients (Fig. 3A).

Considering the impact of other factors from the adjuvant chemotherapy, subgroup analysis was performed for the combined data of NSCLC patients at stages II-III. As shown in Table III, no significant effects of the ERCC1 expression on DFS or OS were observed for the NSCLC patients at stage I (Figs. 2B and 3B). For the NSCLC patients at stages II-III, no significant association was observed between the ERCC1 expression and DFS (Fig. 2C), while the 3-year OS for ERCC1-negative patients $(74.2 \%)$ was significantly higher than the ERCC1-positvie patients $(56.1 \%)(\mathrm{P}<0.05)$ (Fig. 3C). These results suggest that the elevated expression of ERCC1 
Table II. Prognostic analysis of the tumor ERCC1 expression in NSLCL patients.

\begin{tabular}{|c|c|c|c|c|c|}
\hline & \multirow[b]{2}{*}{ Total } & \multicolumn{2}{|c|}{ Tumor ERCC1 expression } & \multirow[b]{2}{*}{$\chi^{2}$} & \multirow[b]{2}{*}{ P-value } \\
\hline & & Positive & Negative & & \\
\hline DFS & & & & 4.758 & 0.029 \\
\hline Recurrence/total, $\mathrm{n}$ & $78 / 140$ & $37 / 65$ & $41 / 75$ & & \\
\hline 1 year DFS rate & $70.9 \%$ & $79.8 \%$ & $85.9 \%$ & & \\
\hline 2 years DFS rate & $51.0 \%$ & $69.1 \%$ & $76.8 \%$ & & \\
\hline 3 years DFS rate & $33.7 \%$ & $53.4 \%$ & $66.8 \%$ & & \\
\hline Median DFS, m (95\%CI) & $24.57(19.6-29.54)$ & $22.17(9.85-34.49)$ & $28.40(19.34-37.46)$ & & \\
\hline OS & & & & 6.502 & 0.011 \\
\hline Death/total, $\mathrm{n}$ & $30 / 140$ & $19 / 65$ & $11 / 75$ & & \\
\hline 1 year OS rate & $97.7 \%$ & $88.4 \%$ & $94.2 \%$ & & \\
\hline 2 years OS rate & $92.3 \%$ & $67.9 \%$ & $87.1 \%$ & & \\
\hline 3 years OS rate & $89.8 \%$ & $64.7 \%$ & $84.2 \%$ & & \\
\hline Median OS, m (95\%CI) & - & $51.93(41.686-62.174)$ & - & & \\
\hline
\end{tabular}

ERCC1, excision repair cross-complementation 1; NSCLC, non-small cell lung cancer; DFS, disease-free survival; OS, overall survival.
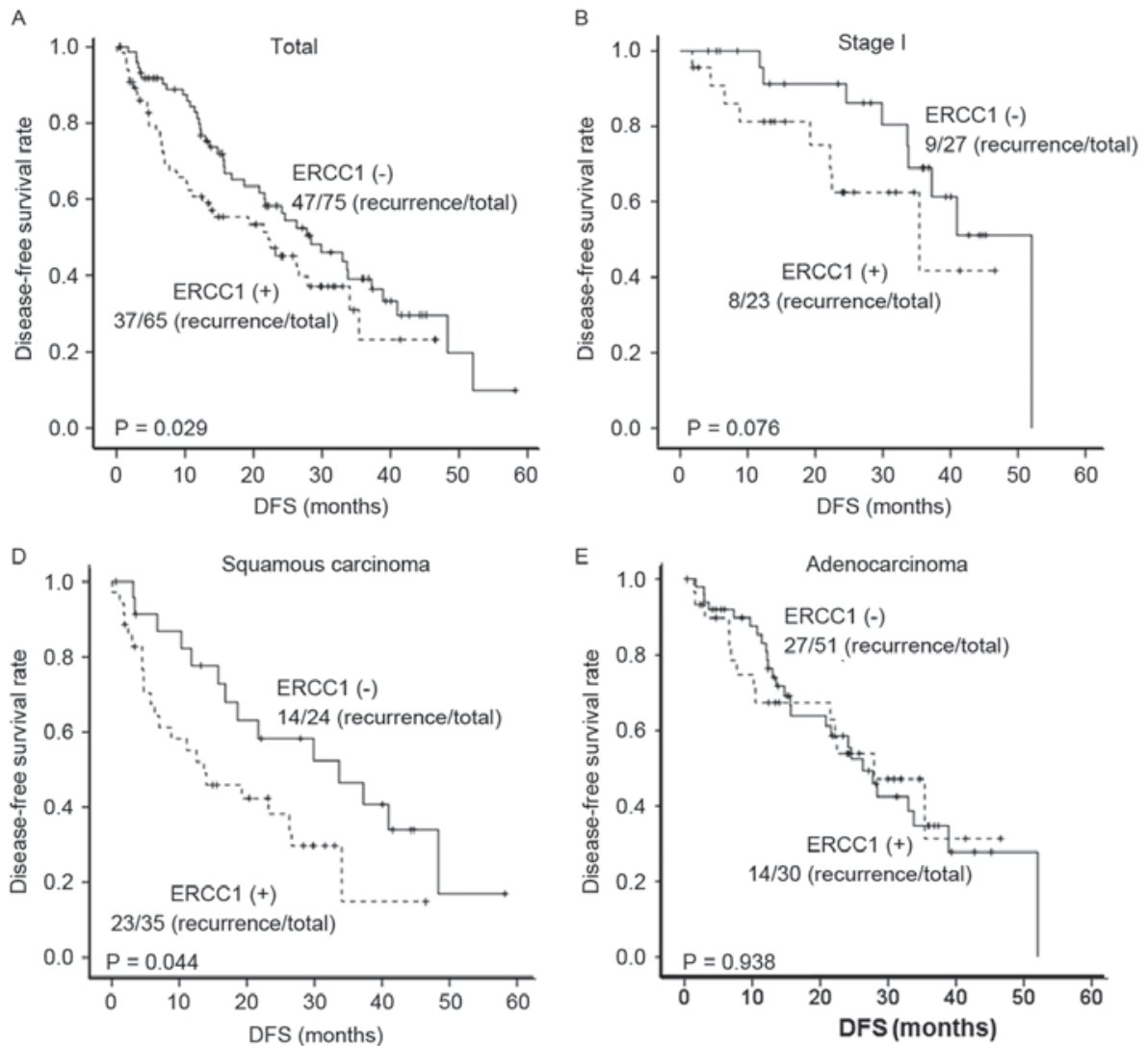

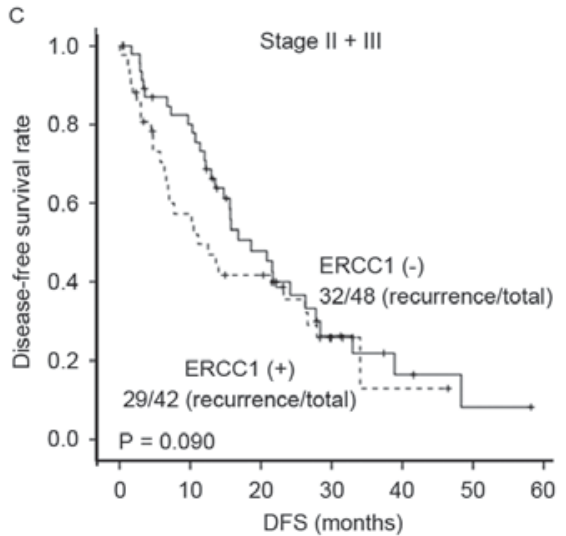

Figure 2. Effects of ERCC1 expression on the DFS of patients. (A) Effects of ERCC1 expression on the DFS of NSCLC patients. (B and C) Effects of ERCC1 expression on the DFS of NSCLC patients at stages I (B) and II-III (C). (D) Effects of ERCC1 expression on the DFS of patients with squamous carcinoma. (E) Effects of ERCC1 expression on the DFS of patients with adenocarcinoma. ERCC1, excision repair cross-complementation 1; NSCLC, non-small cell lung cancer; DFS, disease-free survival.

in the NSCLC patients who need the postoperative adjuvant chemotherapy may indicate the tumor resistance.
Since the expression level of ERCC1 for the squamous carcinoma was higher than the adenocarcinoma, according 

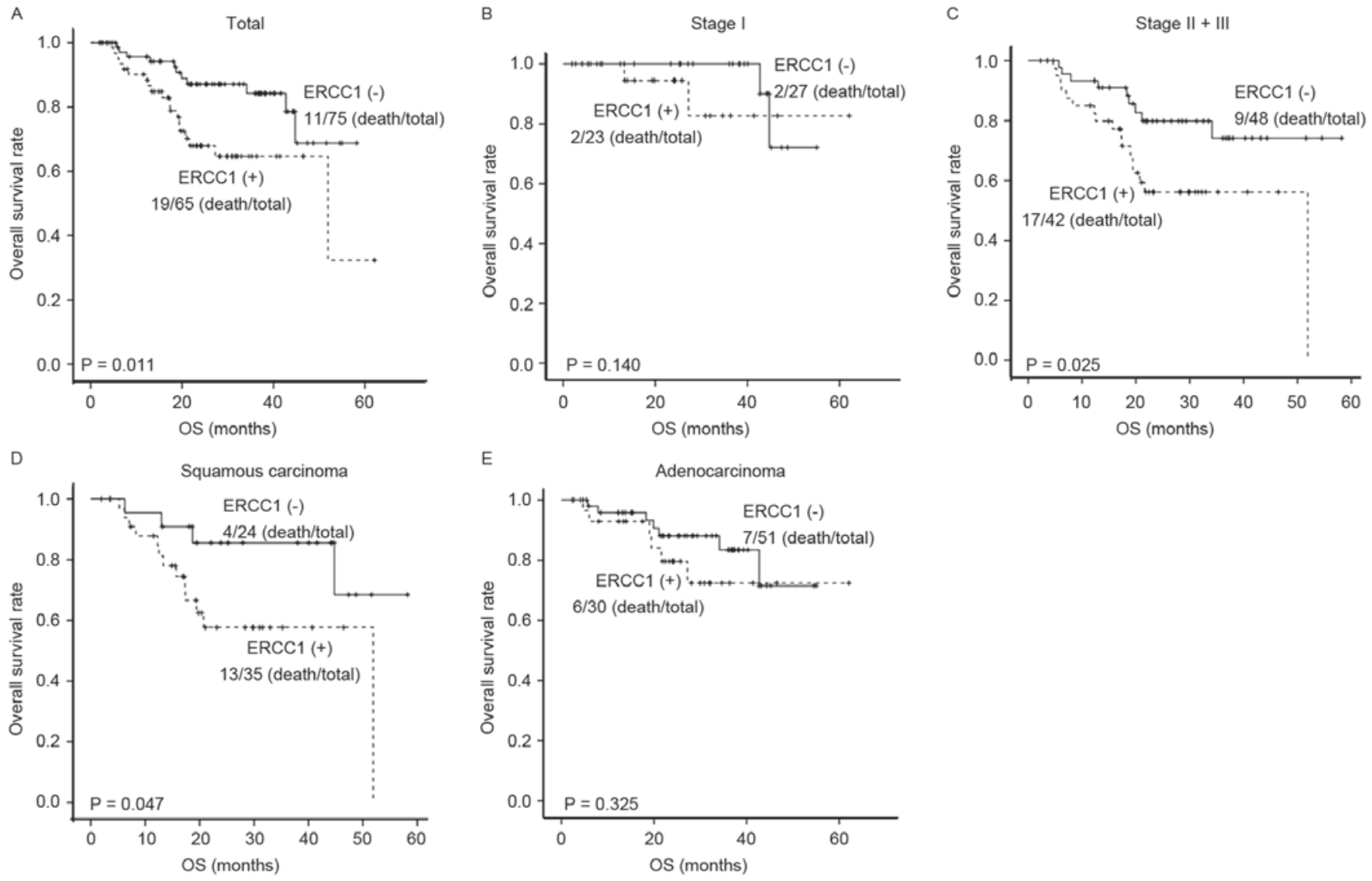

Figure 3. Effects of ERCC1 expression on the OS of patients. (A) Effects of ERCC1 expression on the OS of NSCLC patients. (B and C) Effects of ERCC1 expression on the OS of NSCLC patients at stages I (B) and II-III (C). (D) Effects of ERCC1 expression on the OS of patients with squamous carcinoma (E) Effects of ERCC1 expression on the OS of patients with adenocarcinoma. ERCC1, excision repair cross-complementation 1; NSCLC, non-small cell lung cancer; OS, overall survival.

subgroup analysis was further conducted. As shown in Table IV, the 3-year DFS and OS rates for the patients with ERCC1-negative squamous carcinoma were 40.7 and $68.4 \%$, respectively, with the median DFS of $13.63 \mathrm{~m}$ (ranging from 2.73 to $24.53 \mathrm{~m}$ ). On the other hand, the 3-year DFS and OS rates for the patients with ERCC1-positie squamous carcinoma were 14.8 and $57.7 \%$, respectively, with the median DFS of $33.63 \mathrm{~m}$ (ranging from 13.95 to $53.31 \mathrm{~m}$ ). The Kaplan-Meier survival analysis showed that the DFS and OS rates of the patients with ERCC1-negative squamous carcinoma were superior to the ERCC1-positive patients (both $\mathrm{P}<0.05$ ) (Figs. 2D and 3D). For the adenocarcinoma, the 3-year DFS and OS rates for the ERCC1-negative patients were 27.8 and $83.4 \%$, respectively, with the median DFS of $27.93 \mathrm{~m}$ (ranging from 17.55 to $38.31 \mathrm{~m}$ ). The 3-year DFS and OS rates for the patients with ERCC1-positive adenocarcinoma were 31.4 and $72.4 \%$, respectively, with the median DFS of $26.27 \mathrm{~m}$ (ranging from 13.95 to $53.31 \mathrm{~m}$ ). No significant effects of ERCC1 expression on the DFS and OS were observed for the patients with adenocarcinoma (Figs. 2E and 3E). In addition, the COX regression multivariate survival analysis showed that the pathologic staging was the only independent factor affecting the patient DFS, while the pathologic staging, T staging, and ERCC1 expression were independent factors affecting the OS of NSCLC patients (Table V).
Inhibition of p38 enhances $A 549$ cell sensitivity to DDP and downregulates ERCC1 expression. Both p38MAPK and ERCC1 are closely related to the tumor resistance. Studies have shown that positive correlation could be observed between the ERCC1 and p-p38 levels in the NSCLC tissues (21). The relationship between p38MAPK and ERCC1, and its effect on the cell tumor resistance, were then investigated. Our results from the MTT assay showed that the treatment of p38 inhibitor, BIRB796, significantly enhanced the sensitivity of A549 cells to cisplatin (Fig. 4A). The mRNA and protein expression levels ofERCC1, and the performance of the p38 signaling pathway, were then investigated. Our results showed that along with the increasing treatment concentrations of cisplatin, the mRNA and protein expression levels of ERCC1, and the level of p-p38, were gradually elevated, which could be significantly declined by the treatment of $10 \mu \mathrm{mol} / \mathrm{LBIRB} 796$ (Fig. 4B and C). These results suggest that the $\mathrm{p} 38$ signaling pathway could exert direct or indirect regulatory effects on the expression of ERCC1.

\section{Discussion}

Platinum-based two-drug combined chemotherapy is an important therapeutic method for the treatment of NSCLC, however, with the overall efficiency rate of only $20-40 \%$. With the rapid development of molecular biology in recent years, the interference of ERCC1 expression has been shown 
Table III. Prognostic analysis of the tumor ERCC1 expression in NSLCL patients at stages I and II-III.

\begin{tabular}{|c|c|c|c|c|c|}
\hline \multirow[b]{2}{*}{ Variable } & \multirow[b]{2}{*}{ Total } & \multicolumn{2}{|c|}{ Tumor ERCC1 expression } & \multirow[b]{2}{*}{$\chi^{2}$} & \multirow[b]{2}{*}{ P-value } \\
\hline & & Positive & Negative & & \\
\hline \multicolumn{6}{|l|}{ Stage I } \\
\hline Recurrence/total, $\mathrm{n}$ & $17 / 50$ & $8 / 23$ & $9 / 27$ & 3.143 & 0.076 \\
\hline 3-years DFS rate & $59.7 \%$ & $41.7 \%$ & $69.0 \%$ & & \\
\hline Median DFS, m (95\%CI) & $40.97(35.213-46.727)$ & $35.4(12.702-58.098)$ & 52.03 & & \\
\hline Death/total, $\mathrm{n}$ & $4 / 50$ & $2 / 23$ & $2 / 27$ & 2.180 & 0.140 \\
\hline 3-years OS rate & $85.8 \%$ & $82.6 \%$ & $90.0 \%$ & & \\
\hline Median OS, m (95\%CI) & - & - & - & & \\
\hline \multicolumn{6}{|l|}{ Stage II-III } \\
\hline Recurrence/total, $\mathrm{n}$ & $61 / 90$ & $29 / 42$ & $32 / 48$ & 2.869 & 0.090 \\
\hline 3-years DFS rate & $19.9 \%$ & $12.9 \%$ & $21.8 \%$ & & \\
\hline Median DFS, m (95\%CI) & $15.67(9.122-22.218)$ & $11.1(3.972-18.228)$ & $18.6(11.762-25.438)$ & & \\
\hline Death/total, $\mathrm{n}$ & $26 / 90$ & $17 / 42$ & $9 / 48$ & 5.001 & 0.025 \\
\hline 3-years OS rate & $64.7 \%$ & $56.1 \%$ & $74.2 \%$ & & \\
\hline Median OS, m (95\%CI) & $51.93(22.646-81.214)$ & - & - & & \\
\hline
\end{tabular}

ERCC1, excision repair cross-complementation 1; NSCLC, non-small cell lung cancer; DFS, disease-free survival; OS, overall survival.

Table IV. Prognostic analysis of the tumor ERCC1 expression in patients with squamous carcinoma and adenocarcinoma.

\begin{tabular}{|c|c|c|c|c|c|}
\hline \multirow[b]{2}{*}{ Variable } & \multirow[b]{2}{*}{ Total } & \multicolumn{2}{|c|}{ Tumor ERCC1 expression } & \multirow[b]{2}{*}{$\chi^{2}$} & \multirow[b]{2}{*}{ P-value } \\
\hline & & Positive & Negative & & \\
\hline \multicolumn{6}{|l|}{ Squamous carcinoma } \\
\hline Recurrence/total, $\mathrm{n}$ & $37 / 59$ & $23 / 35$ & $14 / 24$ & 4.042 & 0.044 \\
\hline 3-years DFS rate & $28.1 \%$ & $14.8 \%$ & $40.7 \%$ & & \\
\hline Median DFS, m (95\%CI) & $21.70(10.611-32.789)$ & $33.63(13.948-53.312)$ & $13.63(2.731-24.529)$ & & \\
\hline Death/total, n & $17 / 59$ & $13 / 35$ & $4 / 24$ & 3.948 & 0.047 \\
\hline 3-years OS rate & $69.8 \%$ & $57.7 \%$ & $68.4 \%$ & & \\
\hline Median OS, m (95\%CI) & $51.93(41.686-62.174)$ & - & - & & \\
\hline \multicolumn{6}{|l|}{ Adenocarcinoma } \\
\hline Recurrence/total, $\mathrm{n}$ & $41 / 81$ & $14 / 30$ & $27 / 51$ & 0.006 & 0.938 \\
\hline 3-years DFS rate & $29.8 \%$ & $31.4 \%$ & $27.8 \%$ & & \\
\hline Median DFS, m (95\%CI) & $27.77(21.861-33.679)$ & 26.27(13.948-53.312) & $27.93(17.549-38.311)$ & & \\
\hline Death/total, $\mathrm{n}$ & $13 / 81$ & $6 / 30$ & $7 / 51$ & 0.97 & 0.325 \\
\hline 3-years OS rate & $79.1 \%$ & $72.4 \%$ & $83.4 \%$ & & \\
\hline Median OS, m (95\%CI) & - & - & - & & \\
\hline
\end{tabular}

ERCC1, excision repair cross-complementation 1; DFS, disease-free survival; OS, overall survival.

to be able to enhance the sensitivity of a variety of tumor cells to platinum drugs, including lung, colon, liver, and ovarian cancers (22-25). Olaussen et al (26) have shown that according to the immunohistochemical staining for the NSCLC patients at stages I-III after radical resection, the ERCC1-negatie patients could benefit from the platinum-based chemotherapy, while ERCC1-overexpressing patients could not. These findings suggest that ERCC1 overexpression might be associated with the platinum resistance. Sad et al (7) have investigated the chemotherapy for locally progressed NSCLC, and they suggest that the OS and progression-free survival for the ERCC1-negative patients would be longer 
Table V. COX regression multivariate survival analysis for NSCLC patients.

\begin{tabular}{|c|c|c|c|c|c|c|c|c|c|}
\hline \multirow[b]{2}{*}{ Survival } & \multirow[b]{2}{*}{ Variables } & \multirow[b]{2}{*}{$\beta$} & \multirow[b]{2}{*}{$\mathrm{SE}$} & \multirow[b]{2}{*}{ Wald } & \multirow[b]{2}{*}{$\mathrm{df}$} & \multirow[b]{2}{*}{ P-value } & \multirow[b]{2}{*}{$\operatorname{Exp}(\beta)$} & \multicolumn{2}{|c|}{$\begin{array}{c}95.0 \% \mathrm{CI} \\
\text { for } \operatorname{Exp}(\beta)\end{array}$} \\
\hline & & & & & & & & Up & Down \\
\hline DFS & pTNM & 0.747 & 0.146 & 26.304 & 1 & 0.000 & 2.110 & 1.586 & 2.807 \\
\hline \multirow[t]{3}{*}{ OS } & pTNM & 0.972 & 0.293 & 11.042 & 1 & 0.001 & 2.644 & 1.490 & 4.691 \\
\hline & $\mathrm{T}$ stage & 0.402 & 0.199 & 4.057 & 1 & 0.044 & 1.494 & 1.011 & 2.209 \\
\hline & ERCC1 & 0.803 & 0.385 & 4.352 & 1 & 0.037 & 2.231 & 1.050 & 4.742 \\
\hline
\end{tabular}

ERCC1, excision repair cross-complementation 1; NSCLC, non-small cell lung cancer; DFS, disease-free survival; OS, overall survival.

A

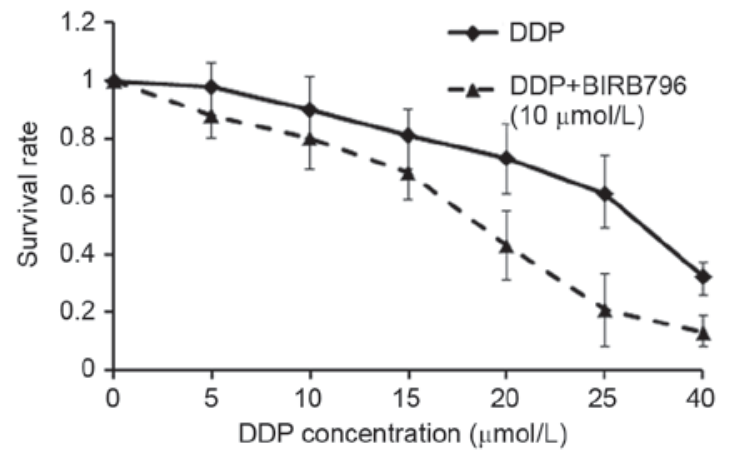

B

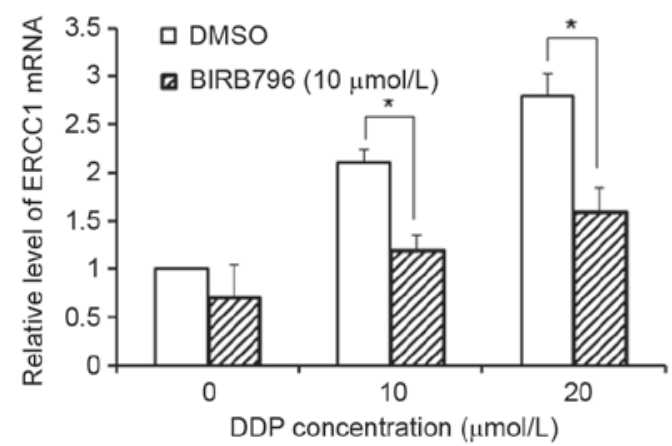

。

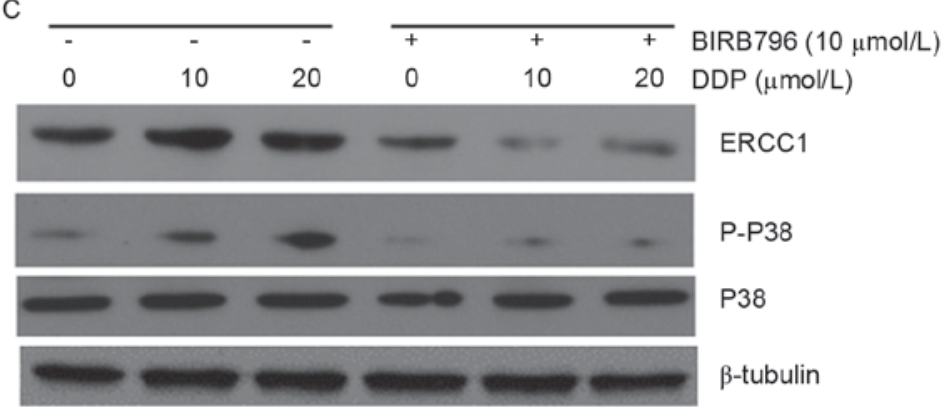

Figure 4. Effects of p38 inhibition on the A549 cell sensitivity to DDP and the ERCC1 expression. (A) Proliferation of A549 cells treated with DDP or DDP+BIRB796 (10 $\mu \mathrm{mol} / \mathrm{l})$ was assessed with the MTT assay. (B and C) A549 cells were treated with $10 \mu \mathrm{mol} / 1 \mathrm{BIRB} 796$ for $1 \mathrm{~h}$, followed by DDP treatment at indicated concentrations for $24 \mathrm{~h}$. The mRNA expression level (B) of ERCC1, as well as the protein expression levels (C) of p38, p-p38, and ERCC1 were detected with western blot analysis and real-time PCR, respectively. Compared with the control group, "P<0.01. DDP, diamminedichloroplatinum; ERCC1, excision repair cross-complementation 1.

for the ERCC1-positive patients. Hubner et al (18) have also shown that the elevated ERCC1 expression in NSCLC patients who have received platinum-based treatment would imply poor prognosis, which is however not the case for the naïve patients. Moreover, NSCLC patients overexpressing ERCC1 exhibit resistance against platinum-based therapy. Therefore, it has been accepted that the expression of ERCC1 is an important predictor for the prognosis of platinum-based chemotherapy for locally progressed lung cancer. Our results demonstrated that for the NSCLC patients after surgery, the ERCC1-negative patients have longer DFS and OS compared with the ERCC1-positive patients. Subgroup analysis showed that the OS for ERCC1-negative patients at stages II-III was significantly longer than the ERCC1-positive patients. However, no significant differences in DFS were observed between the ERCC1-negative and -positive NSCLC patients. These findings suggest that the NSCLC patients at stages II-III who receive platinum-based adjuvant chemotherapy would benefit from the negative expression of ERCC1. However, these is still no widely accepted objective criteria for the expression of ERCC1, and the majority of investigations are retrospective studies using the median split method, which would inevitably result in subjective bias in sampling, limiting its clinical application.

Our results showed that the expression levels of ERCC1 were elevated in the tumor tissues from the patients with 
squamous carcinoma and those had long-term smoking habit. The expression of ERCC1 in the lung squamous carcinoma tissue was significantly higher than the adenocarcinoma tissue, which was in line with the findings from Olaussen et al (26). The prognosis analysis also showed that in the patients with squamous carcinoma, the 3-year DFS and OS rates for the ERCC1-negative patients were significant higher than the ERCC1-positive patients. Moreover, the expression rate of ERCC1 was significantly higher for the long-term smoking patients than the non-smokers. Studies have shown that smoking could not only cause DNA damage and stimulate DNA repairing (27), but also activate p-p38 in the lung tissue of mice $(28,29)$ and induce bronchial squamous metaplasia $(30,31)$. The present study preliminarily confirmed that the p38 inhibitor could suppress the expression of ERCC1 via blocking the p38 signaling pathway. Based on these findings, we hypothesize that as exogenous stimuli, tobacco could activate the p38 signaling pathway to enhance the expression of ERCC1. Of course, further studies are still needed to confirm the hypothesis.

In conclusion, our results showed that the expression of ERCC1 in the NSCLC tumor tissue was an important indicator for the disease prognosis, especially for the patients at stages II-III who received systematic platinum-based chemotherapy. Moreover, the expression rates of ERCC1 were elevated for patients with squamous carcinoma and with smoking habit. Prognosis of ERCC1-negative patients with squamous carcinoma was superior to the ERCC1-positive patients. Furthermore, the p38 signaling pathway may directly or indirectly regulate the expression of ERCC1. These findings suggest a promising role of ERCC1 expression as the indicator for the clinical treatment and prognostic prediction of NSCLC.

\section{Acknowledgements}

This work was supported by the China National Natural Sciences Foundation (no. 81460354) and the Xinjiang Medical University Innovation Fund (XJC201376).

\section{References}

1. Le Chevalier T: Adjuvant chemotherapy for resectable non-small-cell lung cancer: Where is it going? Ann Oncol 7 (Suppl 7): vii196-vii198, 2010.

2. He YW, Zhao ML, Yang XY, Zeng J, Deng QH and He JX: Prognostic value of ERCC1, RRM1 and TS proteins in patients with resected non-small cell lung cancer. Cancer Chemother Pharmacol 75: 861-867, 2015

3. Geredeli C, Artac M, Yildirim S, Inal A, Dede I, Guler T, Boruban MC, Koral L, Karaagac M,Zamani AG, et al: Prognostic value of ERCC1, ERCC2, XRCC1, and TP53 single nucleotide polymorphisms in patients with early-stage non-small cell lung cancer. Tumour Biol 36: 4279-4285, 2015.

4. Pierceall WE, Olaussen KA, Rousseau V, Brambilla E, Sprott KM, Andre F, Pignon JP, Le Chevalier T, Pirker R, Jiang C, et al: Cisplatin benefit is predicted by immunohistochemical analysis of DNA repair proteins in squamous carcinoma but not adenocarcinoma: Theranostic modeling by NSCLC constituent histological subclasses. Ann Oncol 23: 2245-2252, 2012.

5. Bepler G, Zinner RG, Moon J, Calhoun R, Kernstine K, Williams CC, Mack PC, Oliveira V, Zheng Z, Stella PJ, et al: A phase 2 cooperative group adjuvant trial using a biomarker-based decision algorithm in patients with stage I non-small cell lung cancer (SWOG-0720, NCT00792701). Cancer 120: 2343-2351, 2014.
6. Kalikaki A, Voutsina A, Koutsopoulos A, Papadaki C, Sfakianaki M, Yachnakis E, Xyrafas A, Kotsakis A, Agelaki S, Souglakos J, et al: ERCC1 SNPs as potential predictive biomarkers in non-small cell lung cancer patients treated with platinum-based chemotherapy. Cancer Invest 33: 107-113, 2015.

7. Sad LM, Younis SG and Elity MM: Prognostic and predictive role of ERCC1 protein expression in locally advanced stage III non-small cell lung cancer. Med Oncol 31: 58, 2014

8. Sullivan I, Salazar J, Majem M, Pallarés C, Del Río E, Páez D, Baiget $\mathrm{M}$ and Barnadas A: Pharmacogenetics of the DNA repair pathways in advanced non-small cell lung cancer patients treated with platinum-based chemotherapy. Cancer Lett 353: 160-166, 2014.

9. Papadaki C, Sfakianaki M, Ioannidis G,Lagoudaki E, Trypaki M, Tryfonidis K, Mavroudis D, Stathopoulos E, Georgoulias V and Souglakos J: ERCC1 and BRAC1 mRNA expression levels in the primary tumor could predict the effectiveness of the second-line cisplatin-based chemotherapy in pretreated patients with metastatic non-small cell lung cancer. J Thorac Oncol 7: 663-671, 2012.

10. Cobo M, Isla D, Massuti B, Montes A, Sanchez JM, Provencio M, Viñolas N, Paz-Ares L, Lopez-Vivanco G, Muñoz MA, et al: Customizing cisplatin based on quantitative excision repair cross-complementing 1 mRNA expression: A phase III trial in non-small-cell lung cancer. J Clin Oncol 25: 2747-2754, 2007.

11. Roth JA and Carlson JJ: Prognostic role of ERCC1 in advanced non-small-cell lung cancer: A systematic review and meta-analysis. Clin Lung Cancer 12: 393-401, 2011.

12. Li CF, Cao S and Meng SD: Tumor dormancy and identification of therapeutic targets. Ai Zheng 28: 555-558, 2009 (In Chinese)

13. Paillas S, Boissière F, Bibeau F, Denouel A, Mollevi C, Causse A, Denis V, Vezzio-Vié N, Marzi L, Cortijo C, et al: Targeting the p38 MAPK pathway inhibits irinotecan resistance in colon adenocarcinoma. Cancer Res 71: 1041-1049, 2011.

14. Wen J, Cheng HY, Feng Y, Rice L, Liu S, Mo A, Huang J, Zu Y, Ballon DJ and Chang CC: P38 MAPK inhibition enhancing ATO-induced cytotoxicity against multiple myeloma cells. Br J Haematol 140: 169-180, 2008.

15. Ranganathan AC, Adam AP, Zhang L and Aguirre-Ghiso JA: Tumor cell dormancy induced by p38SAPK and ER-stress signaling: An adaptive advantage for metastatic cells? Cancer Biol Ther 5: 729-735, 2006.

16. Ranganathan AC, Zhang L, Adam AP and Aguirre-Ghiso JA: Functional coupling of $\mathrm{p} 38$-induced up-regulation of $\mathrm{BiP}$ and activation of RNA-dependent protein kinase-like endoplasmic reticulum kinase to drug resistance of dormant carcinoma cells. Cancer Res 66: 1702-1711, 2006.

17. He D, Zhao XQ, Chen XG, Fang Y, Singh S, Talele TT, Qiu HJ, Liang YJ, Wang XK, Zhang GQ, et al: BIRB796, the inhibitor of p38 mitogen-activated protein kinase, enhances the efficacy of chemotherapeutic agents in ABCB1 overexpression cells. PLoS One 8: e54181, 2013.

18. Hubner RA, Riley RD, Billingham LJ and Popat S: Excision repair cross-complementation group 1 (ERCC1) status and lung cancer outcomes: A meta-analysis of published studies and recommendations. PLoS One 6: e25164, 2011.

19. Planchard D, Domont J, Taranchon E, Monnet I, Tredaniel J, Caliandro R, Validire P, Besse B, Soria JC and Fouret P: The NER proteins are differentially expressed in ever smokers and in never smokers with lung adenocarcinoma. Ann Oncol 20: $1257-1263,2009$

20. Shi Z, Tiwari AK, Shukla S, Robey RW, Singh S, Kim IW, Bates SE, Peng X, Abraham I, Ambudkar SV, et al: Sildenafil reverses ABCB1- and ABCG2-mediated chemotherapeutic drug resistance. Cancer Res 71: 3029-3041, 2011.

21. Planchard D, Camara-Clayette V, Dorvault N, Soria JC and Fouret P: p38 mitogen-activated protein kinase signaling, ERCC1 expression, and viability of lung cancer cells from never or light smoker patients. Cancer 118: 5015-5025, 2012.

22. Seetharam RN, Sood A, Basu-Mallick A, Augenlicht LH, Mariadason JM and Goel S. Oxaliplatin resistance induced by ERCC1 up-regulation is abrogated by siRNA-mediated gene silencing in human colorectal cancer cells. Anticancer Res 30: 2531-2538, 2010.

23. Ueda S, Shirabe K, Morita K, Umeda K, Kayashima H, Uchiyama H, Soejima Y, Taketomi A and Maehara Y: Evaluation of ERCC1 expression for cisplatin sensitivity in human hepatocellular carcinoma. Ann Surg Oncol 18: 1204-1211, 2011. 
24. Liu GY, Qu QX, Mi RR and Qi J: Relationship between nucleotide excision repair gene ERCC1 and resistance to cisplatin in ovarian cancer. Zhonghua Zhong Liu Za Zhi 30: 184-187, 2008 (In Chinese).

25. Cheong HT, Hui CW, Xu F, Mok TSK and Wong $\mathrm{CH}$ : Abstract 2558: The mechanistic study on the effect of platinum-based chemotherapy efficacy imposed by EGFR-TKI regulated ERCC1 in non-small cell lung cancer (NSCLC). Cancer Res 75: 2558, 2015.

26. Olaussen KA, Dunant A, Fouret P, Brambilla E, André F, Haddad V, Taranchon E, Filipits M, Pirker R, Popper HH, et al: DNA repair by ERCC1 in non-small-cell lung cancer and cisplatin-based adjuvant chemotherapy. N Engl J Med 355: 983-991, 2006.

27. Wei Q, Cheng L, Amos CI, Wang LE, Guo Z, Hong WK and Spitz MR: Repair of tobacco carcinogen-induced DNA adducts and lung cancer risk: A molecular epidemiologic study. J Natl Cancer Inst 92: 1764-1772, 2000.

28. Marwick JA, Kirkham PA, Stevenson CS, Danahay H, Giddings J, Butler K, Donaldson K, Macnee W and Rahman I: Cigarette smoke alters chromatin remodeling and induces proinflammatory genes in rat lungs. Am J Respir Cell Mol Biol 31: 633-642, 2004 .
29. Yao H, Edirisinghe I, Rajendrasozhan S, Yang SR, Caito S, Adenuga D and Rahman I: Cigarette smoke-mediated inflammatory and oxidative responses are strain-dependent in mice. Am J Physiol Lung Cell Mol Physiol 294: L1174-L1186, 2008.

30. Zhong CY, Zhou YM, Douglas GC, Witschi H and Pinkerton KE MAPK/AP-1 signal pathway in tobacco smoke-induced cell proliferation and squamous metaplasia in the lungs of rats. Carcinogenesis 26: 2187-2195, 2005.

31. Bolton SJ, Pinnion K, Oreffo V, Foster M and Pinkerton KE: Characterisation of the proximal airway squamous metaplasia induced by chronic tobacco smoke exposure in spontaneously hypertensive rats. Respir Res 10: 118, 2009. 